28

\title{
How Much Language Do They Need? The Dilemma English-Medium Universities Face When Enrolling English as an Additional Language Students
}

\author{
Janet von Randow \\ University of Auckland, New Zealand
}

Although international and domestic students applying to English-medium universities may well meet the minimum language entry requirement, recent research indicates that this level of language proficiency often does not provide students with the means to cope effectively with their academic studies (Barthel, 2007; Elder, 2003; Read \& Hayes, 2003). To resolve this dilemma our major, multicultural New Zealand university is addressing the problem through implementation of the Diagnostic English Language Needs Assessment (DELNA), a post-entry programme administered to all first-year undergraduate students, regardless of their language background. We use the diagnostic outcomes to guide individual students with particular needs to appropriate forms of academic language enrichment. This paper outlines DELNA's history and administration, student responses to the assessment and the subsequent development and uptake of language support options.

\section{Introduction}

$\mathrm{T}$ he changing demographic of New Zealand society, largely as a result of immigration from the Pacific and Asia over the past four decades, has had a flow-on effect into the tertiary sector. In the 1990s, university teachers, very comfortable with their largely monolingual classes, gradually became aware of a changing student language profile and began to equate higher failure rates in their courses with a lower level of English language proficiency. While language is only one factor contributing to academic success, there does appear to be a level below which students are likely to be at risk of failure (Barthel, 2007; Elder, 2003; Graham, 1987). At the University of Auckland, a many-faceted pathway to university entrance means that not all students enter the University with the same English language qualification, and legally permanent residents for whom English is an additional language could not be asked to take 
an English assessment not required of New Zealand citizens. It was decided, therefore, to introduce the Diagnostic English Language Needs Assessment (DELNA) as a post-entry assessment for all first-year students and to follow this with language support for those in need.

In 2001, while working with the Language Testing Research Centre at the University of Melbourne, we trialled DELNA, and in 2002, the pilot was administered to some 1300 students in departments which had particularly large numbers of permanent resident English as an additional language (EAL) students. As University staff recognised that a language profile of a whole course could inform teaching and learning, the uptake of the assessment spread resulting in it becoming a requirement for all first-year students by 2006. Consequently, the number of language support options across campus increased and uptake of these, the raison d'être of DELNA, has continued to grow.

\section{University Expectations}

The University of Auckland's (2005) intention is to "create and promote a student environment that is welcoming, enjoyable and stimulating, encouraging students to reach their full potential within a climate of academic excellence." It also expects its graduates to have "an ability to access, identify, organise and communicate knowledge effectively in both written and spoken English" (2003). The dilemma is that almost one-third of first-year students each year are unable to take advantage of the stimulating academic environment because of their limited language proficiency, which means that graduate expectations will not be met.

Few students enter university fully equipped with academic literacy skills; many will develop them independently, but others need further instruction and considerable guided practice (Miller, 2006). As the University has spread its net to enrol domestic students from lower socio-economic groups and permanent residents with diverse language backgrounds, and has increased the number of international students (13\% of the student body in 2009), students in need of instruction and practice in order to develop their academic literacy and participate successfully in their degree programmes has grown exponentially.

While it was recognised that many first-year students, irrespective of language background, required academic language instruction, permanent resident EAL students were the initial focus of DELNA. Many, particularly those with some experience of the New Zealand school system, came to the University with very good oral and social communication skills but little academic language proficiency, although they were often unaware of this (Bright $\&$ von Randow, 2008). On the other hand, international students, who gained entrance with the required International English Language Testing System (IELTS) Band, were not a focus until it became obvious that while this gave them university entry it did not mean they would cope effortlessly with the language demands of their degree programmes (Barthel, 2007; Elder, 2003; Read \& Hayes, 2003). Therefore, we made the decision to simply include all first-year students in the DELNA process.

Identifying students' academic English language proficiency at the outset of their studies meant that intervention, where necessary, could begin immediately, allowing them to develop their language skills concurrently with their studies so that they can participate more quickly and more confidently in their courses.

\section{DELNA: A Two-Tiered Assessment}

DELNA comprises an initial 30-minute online screening assessment made up of an academic vocabulary task and a text-editing task, and a finer diagnostic tool - two-hour pen and paper diagnosis of listening, reading, and writing skills.

All first-year students take the online screening, which effectively filters out those (approximately 73\%) whose English proficiency will allow them to develop their academic literacy independently. This

\footnotetext{
${ }^{1}$ The DELNA Handbook can be found at http://www.delna.auckland.ac.nz/delna_handbook.pdf
} 
helps us to quickly and cost-effectively screen over 6,000 first-year students each year. Furthermore, even highly proficient English-speaking students, intrigued with the online assessment, show little reluctance to comply (Read, 2008). Students are immediately notified by email that either (a) their language skills are appropriate for university study; (b) they should brush up their language skills at the Student Learning Centre or at the English Language Self Access Centre; or (c) they should book an appointment to do the diagnosis so that we can identify their language needs and guide them to specific language enrichment programmes.

Diagnostic results are reported on a six-point Band scale: students in Bands 4 and 5 are at risk of failing university courses; those in Band 6 are in need of further English instruction; those in Band 7 may need to work independently on their language skills; and the language skills of high scoring students (Bands 8 and 9) are "unlikely to hamper their academic progress" (Elder, 2003, p.15).

Students receive a language profile with a detailed description of how their proficiency in each skill may affect their academic performance. Those with an average DELNA Band above 6.5 receive their profiles by email, while those with an average DELNA Band below 6.5 are asked to meet with the DELNA Language Adviser to collect and discuss the implications of their profiles and the language support that will suit their degree programme. These options include: academic writing, reading, and listening credit courses at both first and second year; discipline-specific language tutorials in the Business School, Film, Television and Media Studies, Engineering, and Theology; online resources; one-on-one advice and discussion groups at the English Language Self Access Centre; and writing workshops and generic university skills programmes at the Student Learning Centre. While DELNA has become a requirement, language support has been compulsory only in some business courses and Engineering; this is now spreading to Pharmacy, Nursing, and Education. In 2009, the Faculty of Arts joined this group making DELNA and the uptake of appropriate academic writing credit courses mandatory for mature students returning to tertiary study after a break of some years.

\section{The Student Response}

The University has accepted its responsibility to help students develop their academic language proficiency in order to make the most of their studies. It funds DELNA so that it is free for students, encourages the introduction of appropriate language support within faculties, and makes both the Student Learning Centre and the English Language Self Access Centre freely available. Students have a responsibility to help themselves, too, by not only taking DELNA, but also by accessing further language development as advised, which is more effective if they are motivated (Read, 2008).

Initially, we emailed DELNA diagnostic profiles with follow-up advice directly to students and, at the end of that semester, invited them to complete an anonymous online evaluation of their experience with the assessment, studying in English, and taking up language support. Feedback indicated that students were not responding to the advice about language support and we realised we could fix this with a one-on-one interview to discuss their profiles, which many requested. In 2004, the DELNA Academic Language Adviser was appointed and students began to respond positively to the idea that working on their academic English language skills would enhance their university experience.

The presentation of DELNA, from the outset, has been consciously positive (Read, 2008): it is a 'diagnosis' not a 'test'; it is low stakes; it is not a selection tool; it does not affect a student's course choices; there is no pass or fail; and it is free. In spite of this, some students have continued to resist. More seriously, analysis of grades with anecdotal evidence from the University's Counselling Service have shown that these students, approximately 1,000 out of a first-year student intake of approximately 7,000, are largely those most in need. It took some six years to gain wide student acceptance of DELNA; the next step is to have $100 \%$ acceptance and to continue to increase the uptake of language support.

Increasing this uptake, the most important step in the process, is our challenge. A longitudinal interview study of 18 students, three New Zealand citizens, 10 permanent residents, and five interna- 
tional students (Bright \& von Randow, 2004, 2008), coupled with the online student evaluations, highlighted the issues surrounding this and revealed students' attitudes to language support and the role language proficiency played in their final grades. Time, timetable restraints, family commitments, and the fact that they expected their lecturers and tutors to provide language support were given as reasons for non-compliance. When asked to supply a metaphor to describe their first-year experience in an Englishmedium university, interviewees talked of drowning, being buried alive, being in a black hole, struggling uphill with a heavy pack, and in short, suffering and feeling unable to do anything to help themselves.

When 11 of these students were asked on completion of their degrees what they would have done differently, they emphasized that they would have seen the Language Adviser, had that person been available, post DELNA, and taken up the advice. What they advised first-year students in their position to do was what they had largely failed to do: make friends with students whose first language was English and work on language skills consciously from day one.

For students whose language proficiency puts them in the at risk category, it is difficult to take this advice, as coping with course work leaves little time for extra language support. When this is embedded in the course itself, or course related, students have access to discipline-specific language support which is relevant and therefore more effective (Barthel, 2007), they are more likely to attend. This is, therefore, the model we are promoting across the University as faculties take more responsibility for their students' identified academic language needs.

\section{Conclusion}

After eight years of using DELNA, the University of Auckland has become increasingly aware of the academic language needs of its first-year students, and has put measures in place to help students work on these so that they make the most of their university experience and reach their potential.

By assessing all first-year students, irrespec- tive of their language background, DELNA alerts students to the new academic language environment and their need to adapt to it. We are then able to reassure those whose specific language needs are identified, and who then see the DELNA Language Adviser, that they will be helped to acquire the appropriate language skills, but that they too have a role to play in making this happen. Those who avoid DELNA and experience failure and subsequent stress are a concern and we continue to work with faculties and the University Counselling Service to have them acknowledge the benefit of working on their language skills to increase their chance of success and to enhance their whole university experience.

\section{References}

Barthel, A. (2007). Are tertiary students competent in English? Lingua Franca. Retrieved from http://www.abc.net.au/rn/linguafranca/stories/2007/1854124.htm

Bright, C.M. \& von Randow, J. (2004). Tracking language test consequences: The student perspective. Paper presented at the 18th IDP Australian International Education Conference, Sydney, Australia.

Bright, C.M. \& von Randow, J. (2008). Missed opportunities: EAL students reflect on their firstyear language experiences at an English-medium university. Paper presented at the 11th Pacific Rim First Year in Higher Education Conference, Hobart, Tasmania.

Elder, C. (2003, April). The DELNA initiative at the University of Auckland. TESOLANZ Newsletter, 12(1), 15-16.

Graham, J.G. (1987). English language proficiency and the prediction of academic success. TESOL Quarterly, 21(3), 505-521.

Miller, J. (2006). Clash of language, clash of cultures. In M. Stroinska \& V. Cecchetto (Eds.), In- 
ternational classroom dynamics: Challenging the notion of international student. Berlin: Peter Lang Verlag.

Read, J. (2008). Addressing academic language needs through diagnostic assessment. Journal of English for Academic Purposes, 7(3), 180-190.

Read, J. \& Hayes, B. (2003). The impact of IELTS on preparation for academic study in New Zealand. In R. Tulloh (Ed.), IELTS research reports 2003, 4, 153-205.

University of Auckland. (2003). The University of Auckland graduate profile. Retrieved from http://www.auckland.ac.nz/uoa/home/for/ current-students/cs-current-pg/cs-curret-pgprofiles

University of Auckland. (2005). The University of Auckland strategic plan 2005-2012. Retrieved from http://www.auckland.ac.nz/uoa/strategic-plan-2005-2012

\section{Biography}

Janet von Randow has managed the Diagnostic English Language Needs Assessment (DELNA) since its introduction at the University of Auckland in 2002 and has presented the related research at many conferences both in New Zealand and overseas. She first joined the University teaching in the Graduate Diploma of Secondary Teaching after a long career in modern language teaching. Her research interests include language assessment, second language acquisition, and the first-year university experience. 